Taxonomy and systematics

\title{
Description of a new Plusiotis jewel scarab species from Oaxaca, Mexico (Coleoptera: Melolonthidae)
}

\author{
Descripción de un nuevo escarabajo gema de Plusiotis de Oaxaca, México (Coleoptera: \\ Melolonthidae)
}

\author{
Andrés Ramírez-Ponce ${ }^{\mathrm{a}, *}$, Daniel J. Curoe ${ }^{\mathrm{b}}$ \\ ${ }^{a}$ Conacyt-Laboratorio Regional de Biodiversidad y Cultivo de Tejidos Vegetales, Instituto de Biología, UNAM, Ex Fábrica San Manuel de Morcóm s/n, \\ San Miguel Contla, 90640 Santa Cruz Tlaxcala, Tlaxcala, Mexico \\ ${ }^{\mathrm{b}}$ Schiller 524, Colonia Bosques de Chapultepec, Del. Miguel Hidalgo, 11580 Mexico City, Mexico \\ Received 3 April 2017; accepted 24 July 2017 \\ Available online 28 November 2017
}

\begin{abstract}
Plusiotis cosijoezai sp. n. is described from the Sierra Madre del Sur, Oaxaca, in southern México. Habitus and genitalia are illustrated, and diagnostic characters are compared with the closest species, P. lacordairei Boucard.

(C) 2017 Universidad Nacional Autónoma de México, Instituto de Biología. This is an open access article under the CC BY-NC-ND license

(http://creativecommons.org/licenses/by-nc-nd/4.0/).
\end{abstract}

Keywords: Taxonomy; Rutelini; Scarabaeoidea; New species

\section{Resumen}

Se describe a Plusiotis cosijoezai sp. n. de la sierra Madre del Sur, Oaxaca, al sur de México. Se ilustran el hábito y los genitales, y se presentan los caracteres diagnósticos comparándolos con la especie más similar, P. lacordairei Boucard.

(C) 2017 Universidad Nacional Autónoma de México, Instituto de Biología. Este es un artículo Open Access bajo la licencia CC BY-NC-ND

(http://creativecommons.org/licenses/by-nc-nd/4.0/).

Palabras clave: Taxonomía; Rutelini; Scarabaeoidea; Nueva especie

\section{Introduction}

Plusiotis Burmeister, 1844, is a specious Neotropical phytophagous genus, including 103 species that are distributed from southern United States to Ecuador (Márquez, Asiain, Morón, \& Hornung-Leoni, 2013; Monzón, 2012; Morón, 1990; Morón \& Nogueira, 2016). The highest diversity is in Mexico with about 60 species, 43 of which are endemic. Species of this genus have been arranged in 17 (Morón, 1990) or 18 species groups (Hawks, 2001). Morón and Nogueira (2016) referred to

\footnotetext{
* Corresponding author.

E-mail address: andres.ramirez@st.ib.unam.mx (A. Ramírez-Ponce).

Peer Review under the responsibility of Universidad Nacional Autónoma de México.
}

the lack of published morphological and molecular data and analysis to support the synonymization of Plusiotis and Pelidnotopsis Ohaus, 1915 under Chrysina Kirby, 1828 by Hawks (2001), restoring Plusiotis for their revision of the lecontei group (Morón \& Nogueira, 2016). Consequently the generic nomenclature scheme of Morón (1990) is followed in this work.

Our purpose is to describe a new Plusiotis species from the Sierra Madre del Sur in the Mexican state of Oaxaca.

\section{Material and methods}

Morphological characters formed the basis of the present work, and the morphological terminology follows the criteria of Morón (1990) and Morón and Nogueira (2016). All specimens and characters were observed with a Carl Zeiss Stemi 305 
stereomicroscope with an $\mathrm{P} \mid 10 \times / 23$ eyepiece. Measurements were obtained with an ocular micrometer and photographs were taken with a Carl Zeiss Axio Zoom V.16 multifocal stereomicroscope with $\mathrm{P} \mid 10 \times / 23$ eyepieces, a Plan Neo Fluar Z $1 \times / 0.25$, FWD $56 \mathrm{~mm}$ objective and an associated Axiocam 506 color camera. Images were processed and edited in Adobe Photoshop CS5.

We use the phylogenetic species concept, which defines a species as: "the smallest aggregation of (sexual) populations or (asexual) lineages diagnosable by a unique combination of character states" (Wheeler \& Platnick, 2000).

Holotype and allotype material are deposited in the Colección Nacional de Insectos, Instituto de Biología, UNAM (CNIN), and paratypes in the CNIN (2f), Colección Regional de Entomología Tlaxcala (CRTX; $2 \mathrm{f}$ ) and in the private collection of D. Curoe, Mexico City (DJCC; 2 f). Verbatim label data are indicated in quotation marks with slashes to indicate a new line; different labels for each specimen are marked with a different letter in alphabetical order followed by a final parenthesis. The map was created using the SimpleMappr website (Shorthouse, 2010).

\section{Description}

Plusiotis cosijoezai Ramírez-Ponce and Curoe sp. n. Figure 1a-h.

Holotype. Male. Length $31.2 \mathrm{~mm}$; width across humeri $13.0 \mathrm{~mm}$. Color: dorsally apple-green except vertex, periocular areas and clypeus golden pink; pronotal anterior and lateral margins green gold; elytral calla golden (Fig. 1a); epipleural folds golden green (Fig. 1c); ventral coloration green except sternum and ventrites medially with golden pink tinge (Fig. 1b); femora green with bluish tinge, tibiae golden pink with greenish tones, protibial teeth black. Head: clypeus parabolic, without anterior angles; free margin slightly reflexed; disc surface moderately convex, rugopunctate. Frons weakly and uniformly convex, finely, sparcely punctate. Labrum with anterior border broadly and weekly emarginate with 2 medial denticles. Mandibles with incisive tooth large, wide. Labium broadly emarginate with 2 medial rounded denticles. Antennal club longer than preceeding 6 antennomeres. Pronotum: width length ratio 1.0:1.84. Disc uniformly, sparcely punctate; punctures small, shallow. Anterior angles acute, posterior angles obtuse; anterior margin beaded only behind eyes, lateral margins subangulate and strongly beaded, posterior margin with bead effaced anterior to scutellum (Fig. 1a). Elytra: surface punctate-striate; striae deeply impressed, punctures medium in size, deep, separated by 1-2 puncture diameters; apical ends of striae 2 and 9 connected under apical calla. Interstriae moderately convex, irregularly punctate; punctures of various sizes, shallower than those in striae (Fig. 1a). Lateral margin beaded to apical curve; epipleura (ventral view) extending to level of first abdominal sternite. Pygidium: in lateral view, proximal three fourths flat, distal fourth strongly convex (Fig. 1c); surface entirely transversely rugose. Disc glabrous, lateral borders and apex with scattered setae of medium length. Venter: mesometasternal process elongate, exceeding level of mesocoxae (Fig. 1b); apex rounded in ventral view (Fig. 1b), acute in lateral view
(Fig. 1c). Metasternum medially sparcely, minutely punctate; punctation becoming laterally denser, larger, deeper, setigerous; setae posteriorly slanted, thick, rufous (Fig. 1b). Legs: proximal tooth small, apex dull; middle tooth longest; distal tooth curved (Fig. 1a). Mesotibiae with 1 carina. Metafemoral surface almost glabrous, with 3-5 aligned setae near posterior margin. Metatibiae moderately and gradually widened toward apex, with 2 carinae; proximal carina poorly defined (Fig. 1c). Genitalia: parameres tapering apically; lateral margins convex, almost symmetrical (Fig. 1d, e); apex shallowly indented (Fig. 1f); in lateral view slightly convex with apex weakly deflected (Fig. 1g). Ventral plates not fused, sclerotized (Fig. 1d); apical margins inwardly diagonal and broadly emarginate (Fig. 1d).

Allotype. Female. Length $28.4 \mathrm{~mm}$, humeral width $12.45 \mathrm{~mm}$. Similar to male except in the following respects. Color: body entirely light green and tibiae shiny pink with violet tinge; margins of pronotum, scutellum and elytral suture greenish yellow. Head: clypeus notably convex. Legs: protibiae with teeth shorter and with apices more rounded. Genitalia: genital plates wide at base and abruptly narrowed to elongate, subtrapezoidal apex; apices with distal margin outwarly diagonal and crenulate; plates with scattered setae on distal third; setae medium in length, thick, yellowish (Fig. 1h).

Variation in paratypes. Total length $28.3-31.0 .5 \mathrm{~mm}$. Humeral width 12.40-13.0 mm.

Coloration: in one exemplar the vertex, periocular areas and clypeus are ochre- brown, the pronotal disc is slightly yellowish, the elytral interestriae are less convex, and the inferior genital plates have the apex elongated but with the distal edge straight, not oblique.

\section{Taxonomic summary}

Type material ( 8 specimens: $1 \mathrm{~m}, 7 \mathrm{f}$ ). Holotype male labeled: a) "MÉXICO, Oaxaca, Zaachila, / Santa Inés del Monte. / Alumbrado público. / H. M. Guzmán Vásquez Col." (typeset); b) "Bosque de pino-encino. 18-viii-15 / 16 55'32.66" N. / 96 51'41.59" W. / 2335 msnm." (typeset); c) "Plusiotis cosijoezai Ramírez-Ponce y Curoe, 2017. HOLOTIPO” (typeset, red label). Allotype female labeled as holotype except: b) "11-viii-15"; c) "Plusiotis cosijoezai Ramírez-Ponce y Curoe, 2017. ALOTIPO” (typeset, yellow label). Paratypes (2 f): same labels as holotype except: b) "5-x-15"; c) "Plusiotis cosijoezai Ramírez-Ponce y Curoe, 2017. PARATIPO” (typeset, yellow label), and (4 f): same labels as holotype except: a) "D. Curoe col"; b) "20-vi-17"; c) "Plusiotis cosijoezai Ramírez-Ponce y Curoe, 2017. PARATIPO” (typeset, yellow label).

Natural history. The specimens were collected at the end of the rainy season at the street lights of a small town that is surrounded by pine and oak forest under public light in the Sierra Madre del Sur, Oaxaca, southern Mexico (Fig. 2). Their feeding habits and life cycle are unknown.

Temporal data. June (4), August (2) and October (2).

Etymology. Named after the great and fourth sovereign and warrior of the Oaxacan Zaachila dynasty, Cosijoeza, whose name in the zapotec language means "Ray that makes the clouds 

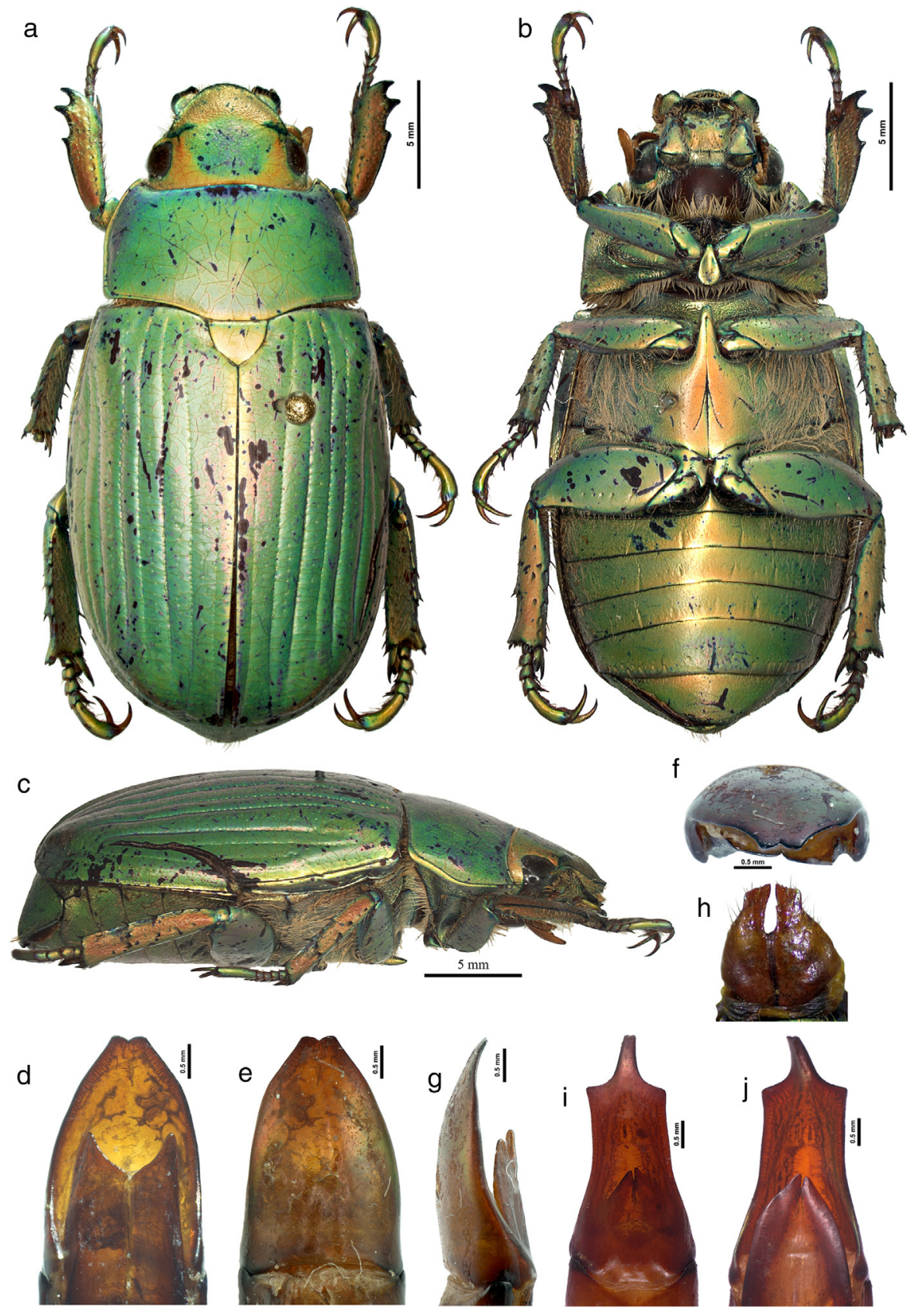

Figure 1. (a-h) Habitus and genitalia of holotype of Plusiotis cosijoezai sp. n. (a) Habitus in dorsal view, (b) habitus en ventral view, (c) habitus in lateral view, (d) parameres in ventral view with detail of ventral plates, (e) parameres in dorsal view, (f) parameres in distal view, (g) parameres in lateral view, (h) genital plates of allotype. (i-j) Male genitalia of P. lacordairei; (i) parameres in dorsal view, (j) parameres in ventra view.

tremble in the wind" (Coxi, ray; xoo, tremble; $e$, wind; y zaa, cloud) (Martínez-Gracida, 1888).

\section{Remarks}

This species can be separated from all other Plusiotis species by the following combination of characters: vertex, periocular areas and clypeus golden pink, anterior and lateral margins of pronotum wodely edged with green gold; parabolic clypeal free margin; labium broadly emarginate with two medial denticles; deeply punctate-striate elytra; mesometasternal process acute in side view; medial protibial tooth longest, and male and female genital form.

P. cosijoezai resembles, and is likely closely related to P. lacordairei Boucard, 1875, a species from Oaxaca and Guerrero. P. lacordairei shares a similar coloration with a silky sheen on the habitus, acute mesometasternal process, and deeply striate elytral surface with $P$. cosijoezai. See Thomas, Seago, and Robacker (2007), for notes on Tyndall light scattering efect, which causes the overlying silky sheen observed on certain Plusiotis species such as P. cosijoezai, P. lacordairei, P. flohri Ohaus, 1905, and P. xalisteca Morón, 1992. However, 


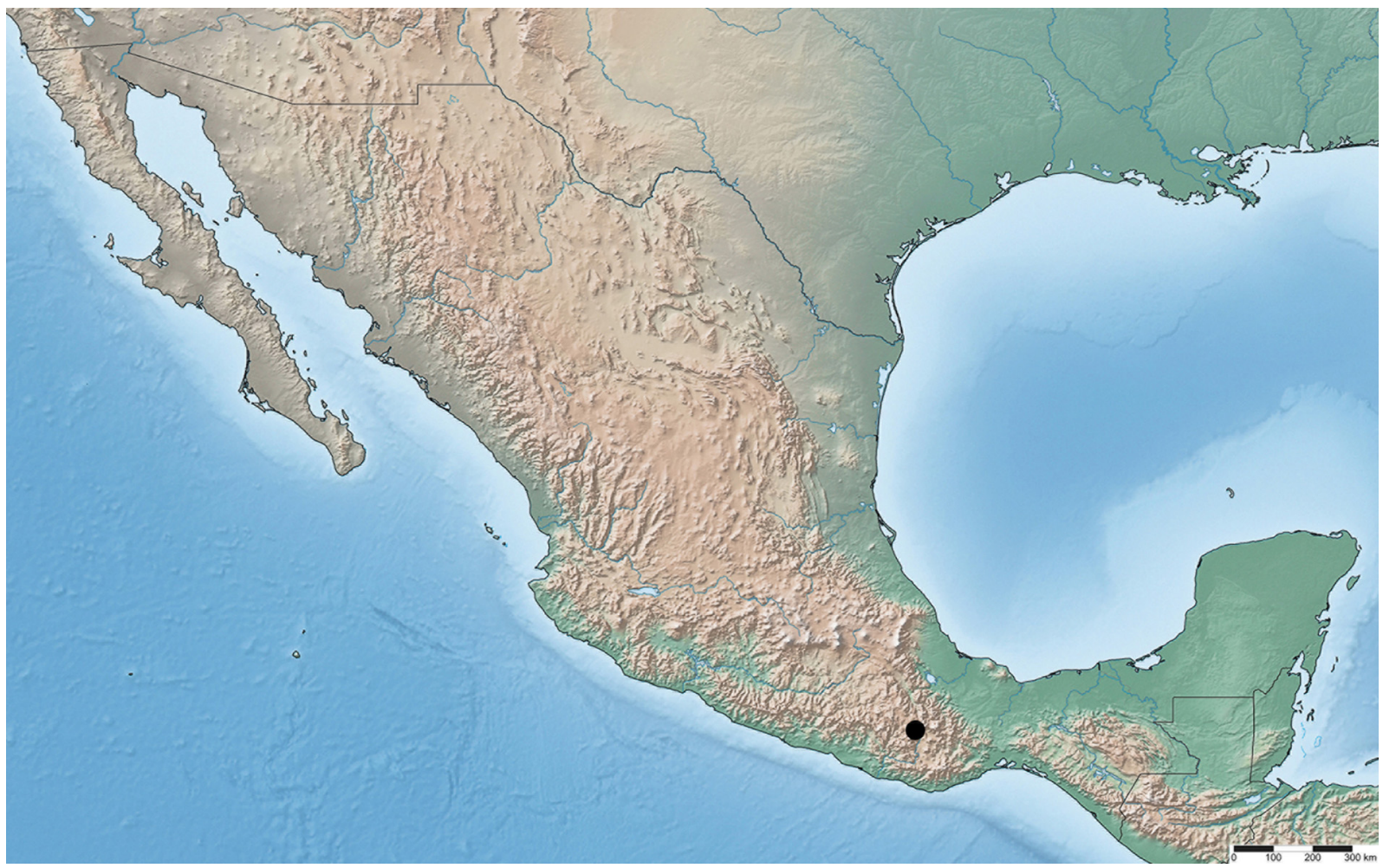

Figure 2. Type locality of Plusiotis cosijoezai sp. $\mathrm{n}$.

its vertex, periocular areas and clypeus are pink whereas in $P$. cosijoezai they are golden pink, rarely ochre-brown. P. lacordairei's frontal punctation is dense with large, deep punctures, and its pygidial surface is imbricately rugopunctate (frontal surface almost smooth and pygidial surface transversely rugose in P. cosijoezai). The parameres in P. lacordairei (Fig. 1i, j) are abruptly narrowed, then evenly tapering and deflecting to narrow, indented apex (parameres with sides convex, tapering to indented apex in P. cosijoezai).

\section{Acknowledgments}

The first author expresses thanks to the program "Cátedras Conacyt" and to the Instituto de Biología, UNAM, for the technical and scientific support given to the project No. 59: "Laboratorio Regional de Biodiversidad y Cultivo de Tejidos Vegetales (LBCTV) del Instituto de Biología (IBUNAM), sede Tlaxcala"; to Conacyt for the Laboratorios Nacionales Conacyt program that allowed to obtain microscopy equipment; to the Secretaría de Fomento Agropecuario del Estado de Tlaxcala, for a support grant as part of the institutional collaboration agreement, to Sergio Cuamatzi Molina for taking the pictures as part of a research stay, and to Héctor Miguel Guzmán Vásquez for the field work during his professional practices. This paper is a contribution to the "Diversidad y distribución de escarabajos lamelicornios del centro y sur de México para evaluar afinidades biogeográficas y prioridades de conservación" project, as part of the "Cátedras Conacyt 059" project.

\section{References}

Hawks, D. (2001). Taxonomic and nomenclatural changes in Chrysina and a synonymic checklist of species (Scarabaeidae: Rutelinae). Occasional Papers of the Consortium Coleopterorum, 4, 1-8.

Márquez, J., Asiain, J., Morón, M. A., \& Hornung-Leoni, C. T. (2013). Escarabajos gema (Insecta: Coleoptera, Melolonthidae) como indicadores del grado de conservación de los bosques de Hidalgo, México. InterCiencia, 38, 410-417.

Martínez-Gracida, M. (1888). El rey Cosijoeza y su familia. Reseña histórica y legendaria de los últimos soberanos de Zaachila. México, D.F.: Oficina Tip. de la Secretaría de Fomento.

Monzón, J. S. (2012). A new species of Chrysina Kirby (Coleoptera: Scarabaeidae: Rutelinae) from Oaxaca, Mexico. Insecta Mundi, 215, 1-4.

Morón, M. A. (1990). The beetles of the World, Volume 10, Rutelini 1: Plusiotis-Chrysina-Chrysophora-Pelidnotopsis-Ectinoplectron. Venecia: Sciences Nat.

Morón, M. A., \& Nogueira, G. (2016). Revisión del grupo de especies "lecontei" de Plusiotis (s. str.) (Coleoptera: Melolonthidae: Rutelinae). Boletín de la Sociedad Entomológica Aragonesa, 58, 6-27.

Shorthouse, D. P. (2010). SimpleMappr, an online tool to produce publicationquality point maps. Retrieved from: http://www.simplemappr.net

Thomas, D. B., Seago, A., \& Robacker, D. C. (2007). Reflections on Golden scarabs. American Entomologist, 53, 224-230.

Wheeler, Q. D., \& Platnick, N. I. (2000). The phylogenetic species concept (sensu Wheeler and Platnick). In Q. D. Wheeler, \& R. Meier (Eds.), Species concepts and phylogenetic theory: a debate (pp. 55-69). New York: Columbia University Press. 